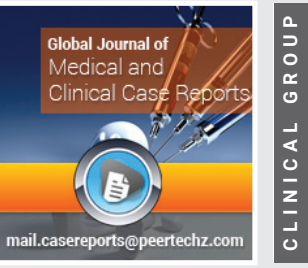

\title{
Eosinophilic enterocolitis: A rare
}

\section{nosological entity}

\author{
K Krati ${ }^{1}$, Y Lemfadli1*, I Boujguenna ${ }^{2}$ and H Rais ${ }^{2}$ \\ ${ }^{1}$ Department of Gastroenterology, Mohamed VI University Hospital Center, Marrakech, Morocco \\ ${ }^{2}$ Department of Pathology, Mohamed VI University Hospital Center, Marrakech, Morocco
}

Received: 28 October, 2020

Accepted: 05 November, 2020

Published: 06 November, 2020

*Corresponding author: Y Lemfadli, Department of Gastroenterology, Mohamed VI University Hospital Center, Marrakech, Morocco,

E-mail: YASSINELEMFADLI@hotmail.com

Keywords: Eosinophilic enteritis; Eosinophilic colitis; Hyper-eosinophilia

https://www. peertechz.com

Check for updates

\section{Abstract}

Eosinophilic enterocolitis is an exceptionally rare disease with few cases described in the literature. It is the least frequent manifestation of the broad spectrum of gastrointestinal eosinophilic diseases. We describe a case of a female patient presenting with a form of the disease manifested by Koenig's syndrome and diarrhea. This posed a diagnostic challenge for us due to its non-specific symptoms, associated with the absence of standardized histological criteria, hence the need for a high level of suspicion. There is also no consensus regarding the treatment. It should be individualized according to the age of the patient and the severity of symptoms.

\section{Introduction}

Eosinophilic enterocolitis is the least common subgroup of the broad spectrum of primary eosinophilic gastrointestinal disorders which can be subdivided into eosinophilic esophagitis, eosinophilic gastritis, eosinophilic enteritis, and eosinophilic colitis [1]. Since the small intestine is not frequently biopsied, there is little evidence related to eosinophilic enteritis [2]. Since 1979 , only a few cases of eosinophilic colitis have been reported [2]. Its exact prevalence remains unknown, with a peak of prevalence in newborns and young adults and without any gender preference [2]. In this article, we present the case of eosinophilic enterocolitis in a 45-year-old woman and we discuss in the light of the data of the literature the diagnostic and therapeutic dilemma of this nosological entity.

\section{Case report}

We report the case of a 45-year-old woman with a history of three miscarriages and one stillbirth. She was admitted with a 3 month history of intermittent watery diarrhea at a rate of 4 to 5 stools per day, without mucus or blood, associated with koenig syndrome in the right iliac fossa. She reported a profound deterioration in general condition with weight loss of $10 \mathrm{~kg}$ over 3 months. Symptoms worsened a week before admission with the onset of edema in the lower limbs. She had no fever or other associated symptoms.

The patient had no history of atopic disease, no known food or drug allergy, and no recent travel abroad.
On physical examination, she was non-feverish with normal vital signs. She was malnourished and dehydrated with cleft muscle and fat panicle. The edema of the lower extremities was soft white on the scoop with an absence of protein in the urine strips. Examination of the abdomen revealed abdominal tenderness of the right iliac fossa without defense or contracture and no other associated signs.

A complete blood count showed hyperleukocytosis (24,000 / mm 3) and eosinophilia (13,496 / mm 3), microcytic hypochromic anemia at $8.9 \mathrm{~g} / \mathrm{dL}$ with ferritinemia at $51 \mathrm{ng} /$ $\mathrm{ml}$. There was an increase in C-reactive protein $(29 \mathrm{mg} / \mathrm{l})$ and hypoalbuminemia $(14.9 \mathrm{~g} / \mathrm{l})$. The other laboratory results are defined in Table 1.

Coproparasitological examination of the stool did not isolate pathogens. The serum immunoglobulin E assay was normal at $31 \mathrm{KU} / \mathrm{l}(\mathrm{N}<150 \mathrm{KU} / \mathrm{l})$ and HIV serology was negative. The myelogram was without abnormalities.

At this stage an infectious attack was initially suspected without being able to rule out an inflammatory or tumor attack.

Due to concern for parasitic infection, the patient was placed on intravenous metronidazole. The abdominal ultrasound did not show any abnormalities apart from two small ovarian cysts. Complement by a CT enteric scan revealed wall thickening of a few ileal loops in the hypogastric region, in the left iliac fossa and in the pelvic floor, measuring $15 \mathrm{~mm}, 17 \mathrm{~mm}$ and $12 \mathrm{~mm}$ respectively, stenosing with upstream stasis. It presents a 
Table 1: Biochemical and hematological parameters.

\begin{tabular}{|c|c|}
\hline Parameters & Results \\
\hline Hemoglobin & 8,9 (g/dL) \\
\hline MCV & $71\left(\mu^{3}\right)$ \\
\hline $\mathrm{MCHC}$ & $24(\mathrm{pg})$ \\
\hline Hematocrit & $27(\%)$ \\
\hline Leukocytes & $24100(/ \mathrm{mm} 3)$ \\
\hline Polynuclear neutrophils & 5543 (/mm3) \\
\hline Polynuclear eosinophils & $13496(/ \mathrm{mm} 3)$ \\
\hline Polynuclear basophils & $0(/ \mathrm{mm} 3)$ \\
\hline Lymphocytes & 4097(/mm3) \\
\hline Monocytes & 964 (/mm3) \\
\hline Platelets & $601000(/ \mathrm{mm} 3)$ \\
\hline Prothrombin & $100(\%)$ \\
\hline $\mathrm{C}$ reactive protein & 29 (mg/L) \\
\hline Natremia & $128(\mathrm{mmol} / \mathrm{L})$ \\
\hline Kalemia & $4(\mathrm{mmol} / \mathrm{L})$ \\
\hline Calcemia & 70 (mmol/L) \\
\hline phosphoremia & 35 (mmol/L) \\
\hline Albumin & $14,9(\mathrm{~g} / \mathrm{L})$ \\
\hline Ferritinemia & $46.8(\mathrm{ng} / \mathrm{mL})$ \\
\hline Total cholesterol & $0,56(\mathrm{~g} / \mathrm{L})$ \\
\hline Urea & $0,16(\mathrm{~g} / \mathrm{L})$ \\
\hline Creatinine & $2(\mathrm{mg} / \mathrm{L})$ \\
\hline 24 hour proteinuria & $0.35(\mathrm{~g} / \mathrm{L})$ \\
\hline $\lg E$ & $31(\mathrm{KU} / \mathrm{l})$ \\
\hline
\end{tabular}

target enhancement by the contrast product with submucosal edema. There was no significant deep lymphadenopathy (Figure 1).

Colonoscopy was without major macroscopic abnormalities apart from erythema in the terminal ileum and colon (Figure 2). Biopsies of the terminal ileum and all segments of the colonic mucosa were taken.

The anatomopathological study revealed an inflammatory infiltration of the ileal mucosa by lymphocytes, plasma cells and eosinophils, estimated at 29 eosinophils per field at high magnification $\mathrm{x} 2$, with the presence of regular lymphoid follicles, compatible with eosinophilic enterocolitis (Figure 3).

Based on the histopathologic findings, serum eosinophilia and the absence of secondary causes of intestinal eosinophilia, the diagnosis of eosinophilic enterocolitis was made.

Our patient began treatment with intravenous prednisone at $1 \mathrm{mg} / \mathrm{kg} /$ day for 7 days and then took over orally. The ionic disturbances and hypoalbuminaemia were corrected parenterally. The course at week 1 and week 2 was marked by clinical improvement in symptoms, despite persistence of peripheral eosinophilia. She was educated on a 6 food elimination diet avoiding peanuts, milk, eggs, soybeans, wheat, and fish. By week three, she no longer showed up for her check-up appointment.

\section{Discussion}

Eosinophilic enterocolitis is a disease entity linked to abnormal infiltration of the intestinal mucosa by polynuclear eosinophils. It is a rare entity on the spectrum of gastrointestinal eosinophilic disorders [3]. Gastroenteritis and eosinophilic colitis represent an estimated incidence of 22 to 28 cases / 100,000 in the United States [4].

The pathogenesis of eosinophilic gastrointestinal disorders is not well understood. They probably result from a complex interaction between environment, genetics and immunological factors [5]. Several epidemiological studies suggest an allergic component, in particular food allergies, which elicits a Th2type immune response leading to the production of cytokines, such as interleukins, IL-4, IL-5, IL-13 and eotaxins-3. This results in intestinal eosinophilia, which further causes local inflammation by releasing toxic cationic proteins [6]. Even less is known about the etiology of primary eosinophilic colitis. It is associated with food allergies and atopy in several cases described [1]. It can probably be both an IgE and non-IgE mediated disease [7].

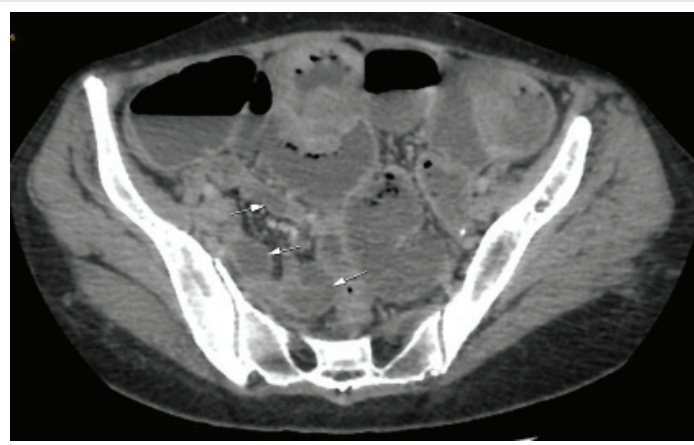

Figure 1: CT scan showing wall thickening of the ileal loops with upstream stasis.

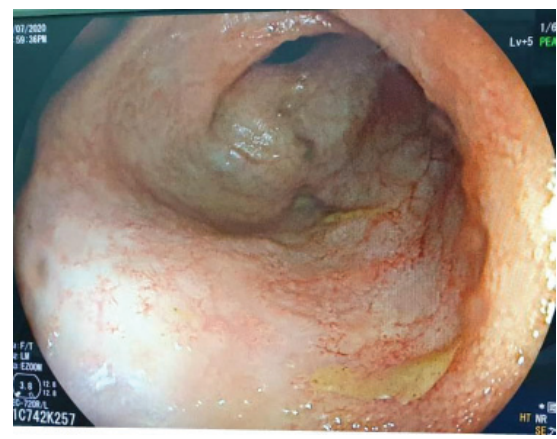

Figure 2: Erythematous ileal mucosa.

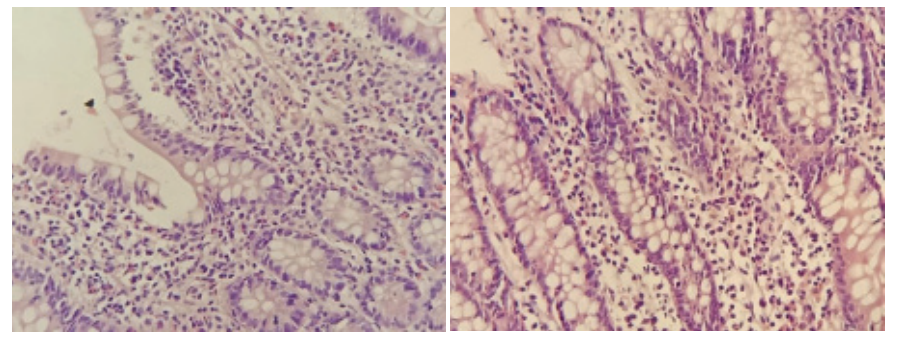

Figure 3: Eosinophilic infiltration of the ileal mucosa (left) and colic (right).

Citation: Krati K, Lemfadli Y, Boujguenna I, Rais H (2020) Eosinophilic enterocolitis: A rare nosological entity. Glob J Medical Clin Case Rep 7(2): 100-102. DOI: https://dx.doi.org/10.17352/2455-5282.000108 
Klein, et al. [8] proposed a classification system based on the depth of parietal infiltration. Mucosal infiltration is the most common type and is characterized by eosinophilic infiltration of the mucosa and sub- mucous membrane. Muscle type is characterized by muscle involvement. The serous type affects all layers and is considered the rarest type [9]. The mucosal type is associated with persistent chronic symptoms and can lead to enteropathy with loss of protein [10].

The diagnosis of eosinophilic enterocolitis is an exclusion diagnosis that requires a high level of suspicion. It is based on the association of non-specific gastrointestinal symptoms, the demonstration of an eosinophilic infiltration on the biopsies, and the exclusion of secondary causes of eosinophilic infiltration such as parasitoses, drugs, chronic inflammatory bowel disease, malignant causes, autoimmune damage and eosinophilic syndrome [7,11]. There are no standardized histological criteria to make the diagnosis [2]. Peripheral eosinophilia can be observed, but may be absent in $20 \%$ of patients. Sectional imaging results are non-specific and may show thickening of the intestinal wall and ascites in some cases [12].

The treatment of eosinophilic enterocolitis remains a challenge in the absence of specific recommendations as there are no controlled trials to date on a specific treatment [9]. So far, the treatment of eosinophilic enterocolitis has been empirical and based on the severity of clinical manifestations, as well as the experience of clinicians. Patients with mild disease can be treated symptomatically, while more symptomatic patients and those with signs of malabsorption need more aggressive treatment [13]

A high proportion of cases of eosinophilic gastroenteritis are associated with food allergy. Therefore, diet therapy may improve symptoms [12]. It involves a "six-food elimination diet," avoiding milk, soy, eggs, wheat, peanuts / tree nuts, and shellfish / fish. The main limitation of diet therapy is patient compliance.

Corticosteroids are the optimal therapy for the induction of remission. Oral prednisone is the most common therapy, with an initial dose of $0.5-1 \mathrm{mg} / \mathrm{kg}$ and decreased over a period of 6-8 weeks. Relapses can occur and require low maintenance doses (1 to $10 \mathrm{mg} /$ day) of prednisolone [14] or the substitution of prednisolone by budesonide which has a better safety profile $[15,16]$.

Other therapies targeting immune modulation have been described in reports, and small case series, will likely be useful in treating recurrent or refractory symptoms. They include mast cell inhibitors such as cromolyn, ketotifen, leukotriene receptor antagonists, anti-IL-5 antibodies, omalizumab, and anti IgE monoclonal antibodies [13].

\section{Conclusion}

Our clinical case highlights a rare entity that is often underdiagnosed. Further studies are needed to better define diagnostic criteria for this entity. Randomized controlled trials are also needed to establish a standardized treatment approach.

\section{References}

1. Alfadda AA, Storr MA, Shaffer EA (2011) Eosinophilic colitis: epidemiology, clinical features, and current management. Therap Adv Gastroenterol 4: 301309. Link: https://bit.ly/352SUUo

2. Bates AWH (2012) Diagnosing eosinophilic colitis: histopathological pattern or nosological entity? Scientifica (Cairo) 2012: 1-9. Link: https://bit.ly/2TZJouE

3. Macaigne G (2018) Colites à éosinophiles de l'adulte. Hépato-Gastro \& Oncologie Digestive 25: 792-802. Link: https://bit.ly/3eypiRy

4. Spergel JM, Book WM, Mays E, Song L, Shah SS, et al. (2011) Variation in prevalence, diagnostic criteria, and initial management options for eosinophilic gastrointestinal diseases in the United States. J Pediatr Gastroenterol Nutr 52 300-306. Link: https://bit.ly/2GykMGp

5. Lopes Azevedo R, Pinto J, Ribeiro H, Pereira F, Leitão C, et al. (2018) Eosinophilic Enterocolitis: An Exceedingly Rare Entity. GE Port J Gastroentero 25: 184-188. Link: https://bit.ly/2Jyq4Tg

6. Cherian ET, Zhang HC, Guttenberg KB, Everett JM, Guha S (2018) Looking Beyond the Obvious: Eosinophilic Enterocolitis, The Am J Med 131: e227-e229. Link: https://bit.ly/3I5RloB

7. Alfadda AA, Storr MA, Shaffer EA (2011) Eosinophilic colitis: an update on pathophysiology and treatment. $\mathrm{Br}$ Med Bull 100: 59-72. Link: https://bit.ly/3n0XA3d

8. Klein NC, Hargrove RL, Sleisenger MH, Jeffries GH (1970) Eosinophilic gastroenteritis. Medicine (Baltimore) 49: 299-319. Link: https://bit.ly/3k4w7eQ

9. Uppal V, Kreiger P, Kutsch E (2016) Eosinophilic gastroenteritis and colitis: a comprehensive review. Clin Rev Allergy Immunol 50: 175-188. Link: https://bit.ly/2I1IAV7

10. Pineton de Chambrun G, Gonzalez F, Canva JY, Gonzalez S, Houssin L, e al. (2011) Natural history of eosinophilic gastroenteritis. Clin Gastroentero Hepatol 9: 950-956. Link: https://bit.ly/3k4pnhh

11. Samiullah, Bhurgri $H$, Sohail U (2016) Eosinophilic disorders of the gastrointestinal tract. Scand J Gastroenterol 43: 1013-1021. Link: https://bit.ly/38gJ9nx

12. Zhang M, Li Y (2017) Eosinophilic gastroenteritis: a state-of-the-art review. J Gastroenterol Hepatol 32: 64-72. Link: https://bit.ly/3mUp7De

13. Sunkara T, Rawla P, Yarlagadda KS, Gaduputi V (2019) Eosinophilic gastroenteritis: diagnosis and clinical perspectives. Clin Exp Gastroenterol 12 239-253. Link: https://bit.ly/3|3jYbj

14. Wong GW, Lim KH, Wan WK, Low SC, Kong SC (2015) Eosinophilic gastroenteritis: clinical profiles and treatment outcomes, a retrospective study of 18 adult patients in a Singap ore Tertiary Hospital. Med J Malaysia 70 232-237. Link: https://bit.ly/2I6ZaRO

15. Busoni VB, Lifschitz C, Christiansen S, GdD MT, Orsi M (2011) Eosinophilic gastroenteropathy: a pediatric series. Arch Argent Pediatr 109: 68-73. Link: https://bit.ly/2Jzt4Pi

16. Lombardi C, Salmi A, Passalacqua G (2011) An adult case of eosinophilic pyloric stenosis maintained on remission with oral budesonide. Eur Ann Allergy Clin Immunol 43: 29-30. Link: https://bit.ly/351dunL

Copyright: ( $) 2020$ Krati K, et al. This is an open-access article distributed under the terms of the Creative Commons Attribution License, which permits unrestricted use, distribution, and reproduction in any medium, provided the original author and source are credited.

Citation: Krati K, Lemfadli Y, Boujguenna I, Rais H (2020) Eosinophilic enterocolitis: A rare nosological entity. Glob J Medical Clin Case Rep 7(2): 100-102. 